\title{
Recorregut de recerca geològica i mineralògica pel pais de Fois I Foix (França): des de Sant Paul de Jarrat, a Freychenet. Col de la Lauze, Montferriér, i a Montsegur
}

Josep Maria Mata-Perelló

Joaquim Sanz Balagué
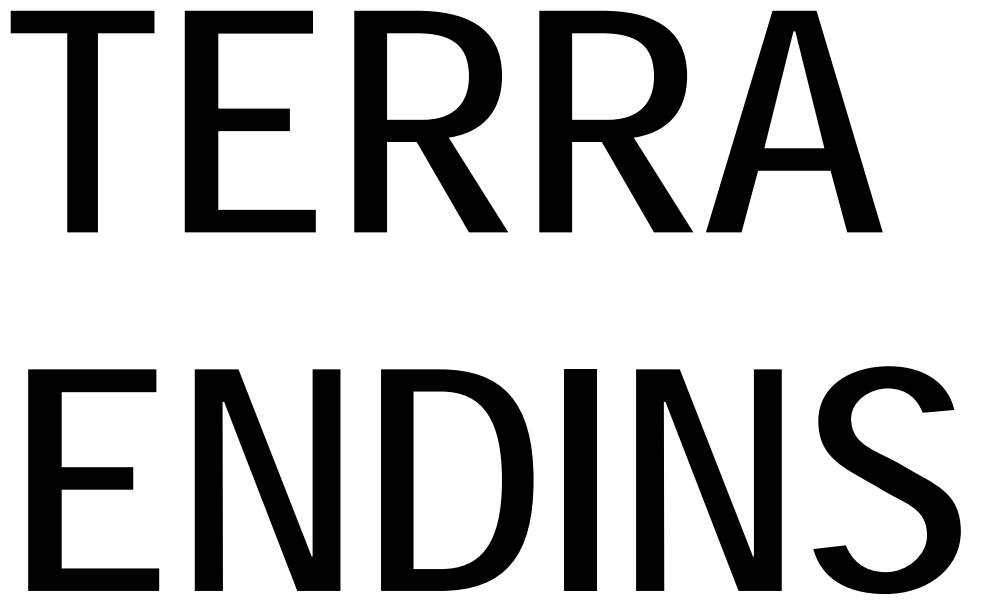

\section{REVSTA DE GEOLOGIA}

\section{n. 2}

JUNY 2015 


\title{
RECORREGUT DE RECERCA GEOLÒGICA I MINERALÒGICA PEL PAIS DE FOIS I FOIX (FRANÇA): DES DE SANT PAUL DE JARRAT, A FREYCHENET. COL DE LA LAUZE, MONTFERRIÉR, I A MONTSEGUR
}

\author{
Josep Maria Mata-Perelló \\ Museu de geologia Valentí Masachs, Escola Politècnica Superior d'Enginyeria de Manresa \\ (EPSEM), Universitat Politècnica de Catalunya · BarcelonaTech (UPC), 08272 Manresa, Spain
}

\section{Joaquim Sanz Balagué}

Departament d'Enginyeria Minera i Recursos Naturals (EMRN), Escola Politècnica Superior d'Enginyeria de Manresa (EPSEM), Universitat Politècnica de Catalunya . BarcelonaTech (UPC), 08272 Manresa, Spain

\section{Paraules clau: Patrimoni geològic i miner ;}

\section{Resum}

Recorregut realitzat el 10 de juliol del 2013. El recorregut del present itinerari, es desenvoluparà íntegrament pel Sistema Pirinenc; distribuint en la seva major part per la Zona Nord Pirinenca. Tot i així, alguns recorreguts es faran dintre de la Zona Axial del Sistema Pirinenc.

Així, el recorregut començarà dintre de la primera unitat, (dintre de l'antigament anomenat Prepirineu Septentrional), per la qual es circularà entre Saint Paul - de - Jarrat i les immediacions de Freychenet. En aquest tram, s'aniran trobant afloraments dels materials mesozoics del Cretàcic.

Posteriorment, el recorregut circularà per l'anomenada Zona Axial Pirinenca (pel Massif de Saint Barthélémy), entre Freychenet i el Col de la Louze. En aquest recorregut, es trobaran afloraments dels materials paleozoics del Devonià i del Carbonífer, fonamentalment.

Posteriorment entre el Col de la Louze i Montsegur, el recorregut discorrerà entre les dues unitats geològiques acabades d'esmentar. Finalment, per les immediacions de Montsegur, cap a la fi del recorregut, l'itinerari anirà situant-se dintre de Zona Nord - Pirinenca.

Per d'altra banda, la totalitat del recorregut es realitzarà pel País de Fois / Foix (és a dir, pel Departament de l'Ariège) per on es realitzarà la totalitat del recorregut, recorrent la vall del riu del mateix nom $i$ algunes de les valls dels seus afluents. 


\section{Objectius fonamentals}

A través d'aquest itinerari geològic-mineralògic, s'intentaran d'aconseguir els següents objectius, acord amb el sentit de la marxa del recorregut.

1.- Estudi i observació de la Zona Nord - Pirinenca (corresponent als antigament denominats Prepirineus Septentrionals) per la qual es circularà fonamentalment a la primera part del recorregut, entre les poblacions de Saint Paul - de - Jarrat i les immediacions de Freychenet. I també cap el tram del recorregut, entre le Col de Louze, Montferriér i Montsegur.

2.- Observació, dels materials mesozoics (fonamentalment del Cretàcic), que constitueixen aquesta Zona Nord - Pirinenca, segons els indrets del recorregut, tot i que predominen sempre els darrers, en aquest itinerari.

3.- Observació de la Zona Axial Pirinenca (Massif de Saint Barthélém). Aquesta zona es tallarà entre Freychenet i el Col de la Louze, cap a la part central del recorregut.

4.- Observació com dels materials paleozoics que constitueixen la Zona Axial Pirinenca. Aquests materials paleozoics pertanyen i fonamentalment pertanyen al Devonià i al Carbonífer, amb un predomini dels primers.

5.- Estudi de les relacions entre les dues unitats geològiques esmentades: entre la Zona Axial Pirinenca i la denominada Zona Nord - Pirinenca.

6.- Observació dels diferents indrets relacionats amb el patrimoni geològic, que anirem trobant al llarg del recorregut del present itinerari

7.- Observació dels diferents indrets relacionats amb el patrimoni miner, que anirem trobant al llarg del recorregut del present itinerari.

\section{Antecedents}

En relació amb el recorregut del present itinerari, no con coneixem l'existència de cap altre que segueixi aquest mateix recorregut. En aquest sentit, aquest recorregut constitueix una primícia, dintre d'aquests tipus de recorreguts.

Per d'altra banda, farem esment de dos treballs de caràcter regional com són els publicats pel BRGM (1979a i 1970b). Tots aquests treballs, i d'altres, figuraran degudament relacionats per ordre alfabètic, i per data de publicació, dintre de l'apartat d'aquest treball dedicat a les referències bibliogràfiques, al gual ens adrecem.

\section{Recorregut de l'itinerari}

El recorregut d'aquest itinerari el començarem a la població de Saint Paul de - Jarrat per on es farà una aturada, prop de la carretera D - 117 (la qual condueix cap a Lavelanet). Poc després, ens caldrà agafar la carretera departamental D - 209, la qual condueix cap a Freychenet. Abans d'arribar-hi, farem una nova aturada.

Després, continuarem per la mateixa carretera (la D - 209) anant cap le Gabachou i cap al Col de Louze. En aquest indret farem una nova aturada. Tot seguit, continuarem cap al poble de Montferriér, des d'on continuarem per la carretera departamental D - 9, la qual condueix cap a Montsegur. A la sortida de Montferrier, farem una nova aturada.

Terra endins.2015 n.2 | Recorregut de recerca geològica i mineralògica pel pais de Fois / Foix (França): des de Sant Paul de Jarrat, a Freychenet. Col de la Lauze, Montferriér, i a Montsegur 
I, finalment, arribarem a Montsegur, tot seguint la carretera D - 9. Rn arribar-hi, farem les dues darreres aturades del recorregut d'aquest itinerari.

\section{Advertiments previs}

Com en altres recorreguts de recerca geològica i mineralògica ..., si es disposa del temps suficient, poden efectuar-se passant per totes les parades i filloles. En cas contrari, recomanem prescindir de les anomenades parades - condicionals.

També recomanem que es demani informació sobre l'estat dels diferents trams de les pistes forestals, per les quals s'ha de circular, en el recorregut de l'itinerari, per tal d'evitar problemes secundàries. En aquesta ocasió, el recorregut transitarà per un tram dificultós: el que ens conduirà des del Port de Pimorent cap a la mina de ferro del mateix nom. aquesta ocasió, aquest recorregut el farem a peu.

Per d'altra banda, i a l'igual que en altres recorreguts semblants, recomanem tenir el màxim de cura i de respecte, entorn de la Natura que ens rodeja.

\section{Descripció de l’itinerari}

Com de costum, estructurarem el recorregut de l'itinerari en una sèrie de PARADES (o d'ESTACIONS), que tot seguit anirem veient. En cadascuna d'aquestes aturades farem un breu comentari (geològic o mineralògic, segons s'escaigui), alhora que indicarem la forma d'arribar-hi en cada cas, tot partint de la parada anterior. Igualment indicarem els trets geològics més representatius, corresponents al trànsit d'una aturada cap a la següent.

Per d'altra banda, en cada cas indicarem, entre parèntesi, el full topogràfic (a escala 1:50.000) on es troba l'aturada. En aquest cas utilitzarem els fulls de I'IGN (Institut Geographique National, de França), que seran els següents fulls: 2147 (o de Foix) i 2247 (o de Lavelanet). La totalitat de les aturades, es realitzarà dintre dels fulls acabats d'esmentar.

Així doncs, la relació ordenada de les aturades que composen aquest recorregut, és la següent:

\subsection{Parada 1. La Tuilerie de Bordeneuve, (Terme de Saint Paul de - Jarrat, País de Fois, Ariège). (Full 2147).}

El recorregut d'aquest itinerari, el començarem prop de la localitat de Saint Paul de - Jarrat, situada a la cruïlla de les carreteres $N-20$ i D - 117. Així, ens caldrà agafar aquesta darrera, per tal de fer una aturada a uns $2^{\prime} 5-3 \mathrm{Km}$ de la cruïlla de carreteres. La parada la farem a I'indret de la Tuilerie, situat prop de Borrdeneuve.

La totalitat d'aquest recorregut, I'hem efectuat entre afloraments dels materials cretàcics que formen part de la Zona Nord - Pirinenca. Tot i així, en aquest indret es troben recoberts per terrenys quaternaris (de l'Holocè), procedents de la terrassa fluvial del Torrent de la Bayre, afluent de l'Arieja.

En aquest indret, hi ha les restes d'una antiga teuleria, en la qual s'aprofitaven els materials argilosos propers. 
Des d'aquest indret es pot efectuar una observació dels relleus mesozoics cretàcics del Picou de Montcamp, entre altres. En aquest indret afloren les roques carbonatades cretàciques del Turonià

\subsection{PARADA 2. Immediacions de le Sourt, (le Sourt, terme de le Gabachou, País de Fois, Ariège). (Full 2147 de l'IGN).}

Des de la parada anterior caldrà continuar cap a llevant, seguint per la carretera departamental D - 117. Més endavant, en arribar a Celles i trobar el trencall (per l'esquerra) d'on eix la carretera D- 209, la qual condueix cap a Freychenet. Tot i així, abans d"arribar a aquesta població, podem fer una nova aturada a le Sourt. Així, des de la parada anterior, haurem efectuat un recorregut d'uns $4 \mathrm{Km}$.

En aquest recorregut, hem continuat trobant els materials esmentats a l'aturada anterior. En efecte, aquest recorregut l'hem efectuat quasi íntegrament per la Zona Nord - Pirinenca, entre afloraments dels materials carbonatats del Cretàcic.

Tot $\mathrm{i}$ així, en aquest indret hi ha el contacte entre aquests materials de la Zona Nord Pirinenca, amb els materials paleozoics de la Zona Axial Pirinenca. Així, ara veiem afloraments dels materials paleozoics carbonatats del Devonià Superior $\mathrm{i}$ dels trams esquistosos del Carbonífer. Aquests materials formen part del Massif de Saint Barthélémy.

Finalment, cal dir que aquest contacte entre els materials paleozoics de la Zona Axial Pirinenca (situada al Sud d'on ara som) i els materials mesozoics de la Zona Nord - Pirinenca (situada al Nord) es produeix per un encavalcament de la primera sobre la segona.

\subsection{PARADA 3. Immediacions del col de louze, (terme de Montferriér, País de Fois, Ariège). (Full 2147 de I’IGN).}

Després de realitzar la parada anterior, cal efectuar un nou recorregut, seguint sempre la carretera departamental D - 209. Així, anirem passant per les poblacions de Freychenet, le Gabachou i la Rasclat, per tal d'arribar finalment a le Col de Louze. Prop d'aquest indret, farem una nova aturada, després de recórrer uns $8 \mathrm{Km}$ des de la parada anterior, aproximadament.

Aquest recorregut I'haurem efectuat íntegrament per la Zona Axial Pirinenca. Així, haurem anant trobant, per tot arreu, afloraments dels materials paleozoics del Devonià (amb nivells carbonatats) i del Carbonífer (amb trams d'esquistos). Tots aquests materials es troben dintre del Massif de Saint Barthélémy.

Per d'altra banda, per les immediacions d'aquest indret, es troba el contacte per encavalcament, dels materials anteriors sobre els materials mesozoics cretàcics de la Zona Nord - Pirinenca. Així, ara anirem trobant afloraments dels materials carbonatats cretàcics, els quals formen part de la unitat geològica acabada d'esmentar.

\subsection{PARADA 4 - condicional. Borda de Bas, (terme de Montferriér, País de Fois, Ariège). (Full 2147 de I’IGN).}

Després de realitzar l'aturada anterior, cal continuar per la carretera departamental D - 209, baixant el Col de Louze i anant cap a llevant. Així, ens anirem apropant a la població de 
Montferriér. En arribar-hi, trobarem la carretera D - 9 (també departamental), procedent de Lavelanet. L'haurem d'agafar, per tal d'anar cap a Montsegur. A la sortida del primer poble esmentat, podem fer una nova aturada, si s'escau. Així, des de la parada anterior, haurem efectuat un recorregut proper als $6 \mathrm{Km}$.

En aquest recorregut. Hem anat trobant afloraments dels materials mesozoics del cretàcic. En efecte, hem anat circulant per la Zona Nord - Pirinenca, on estem ara situats. Tot i així, molt prop d'on ara som, es troben afloraments dels materials carbonatats del Devonià, de la Zona Axial Pirinenca, ja que estem molt a tocar de l'encavalcament que hem travessat a les dues aturades anteriors.

\subsection{PARADA 5. Chateau de Montsegur, (terme de Montsegur, País de Fois I Foix, Ariège), (Fulls 2247).}

Després de fer l'aturada anterior, cal continuar cap al Sud per la carretera departamental D - 9. Així, ens anirem apropant cada vegada més a la població de Montsegur. Poc abans d'arribarhi, farem una nova aturada, a la zona de I'aparcament per pujar fins al cim del castell. Així, des de la parada anterior, haurem efectuat un recorregut proper als $6{ }^{\prime} 5 \mathrm{Km}$, per tal d'arribar fins aquí.

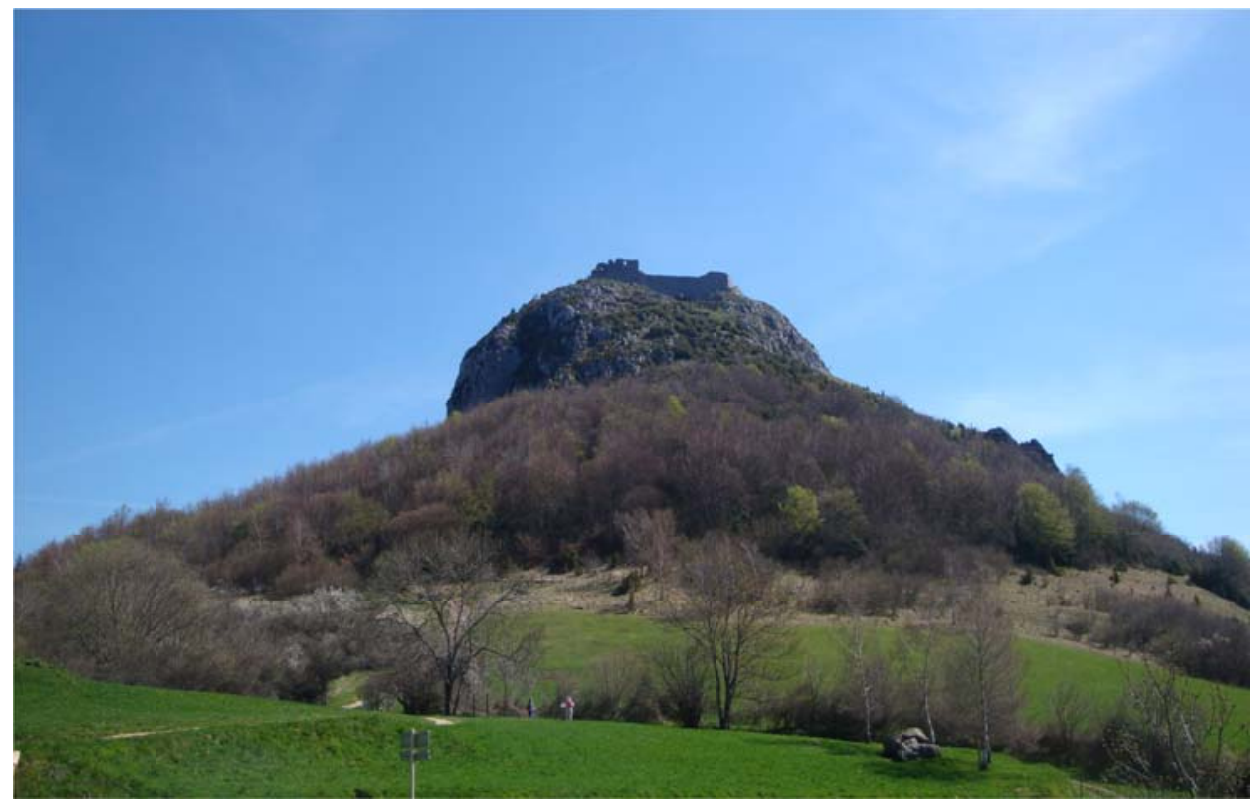

FOTOGRAFIA 1. El Chateau de Montsegur, des de l’apartament

En aquest recorregut, hem anat trobant afloraments dels materials cretàcics que hem esmentat a l'aturada anterior. Efectivament, com a la parada anterior, ens trobem dintre de la Zona Nord - Pirinenca. Així, aquests materials carbonatats cretàcics, es fan palesos per tota arreu, especialment al turó on es troba el castell. En aquest indret, aquests materials pertanyen al Gargasià; això és al Cretàcic Inferior.

Tot i així, prop d'on ara som, es fan palesos els materials cretàcics del Devonià, els quals pertanyen al Massif de Saint Barthélémy; el qual es situa a la Zona Axial Pirinenca. Aquests

Terra endins.2015 n.2 | Recorregut de recerca geològica i mineralògica pel pais de Fois / Foix (França): des de Sant Paul de Jarrat, a Freychenet. Col de la Lauze, Montferriér, i a Montsegur 
materials es troben al Roc de la Gourge i a le Tallat, al SW d'on ara estem situats, als peus del turó del castell de Montsegur.

Des d'aquest indret, es pot veure amplament el turó, desenvolupant sobre uns afloraments de calcàries cretàciques del Gargasià, les quals formen part de l'encavalcament de Montsegur, que també veurem a la propera aturada.(fotografia 1$)$.

\subsection{Parada 6. Poble de Montsegur, (terme de Montsegur, País de Fois I Foix, Ariège), (Fulls 2247).}

Després de realitzar la parada anterior, cal continuar el recorregut cap ell proper poble de Montsegur. Després d'un curt recorregut, de poc més de $1-1^{\prime} 5 \mathrm{Km}$, arribarem al bell mig del poble, per on farem la darrera aturada d'aquest itinerari.

En aquest recorregut, hem anat trobant els materials carbonatats mesozoics del Cretàcic, de caràcter carbonatat. Aquests materials formen part de la Zona Nord - Pirinenca, on ara ens trobem situats.

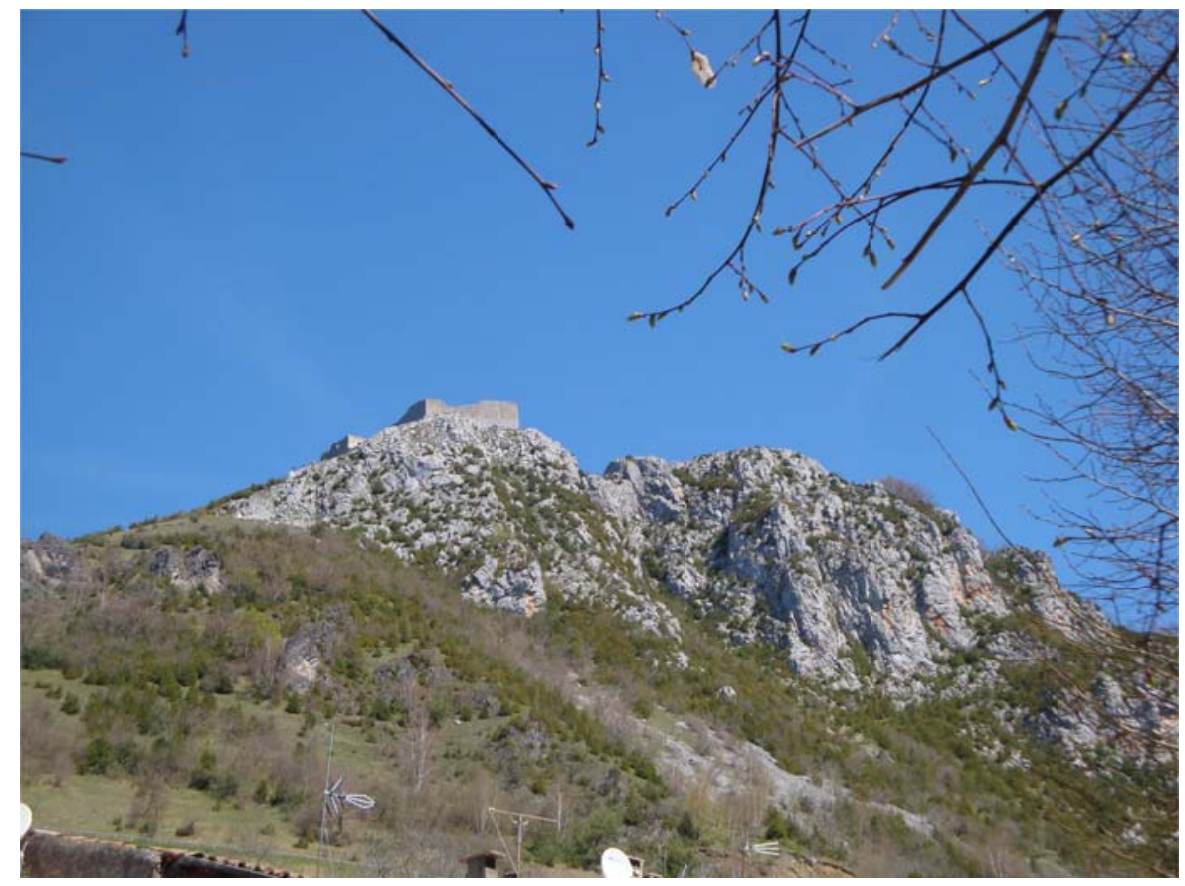

FOTOGRAFIA 2. El Chateau de Montsegur, des del poble de Montsegur

En arribar al bell mig del poble, es fa evident la majestuositat del turó on es troba el Chateau de Montsegur. Així, es situa sobre un aflorament de calcàries cretàciques del Gargasià, les quals formen part de l'encavalcament de Montsegur. (fotografia 2).

Per d'altra banda, des d'aquest indret, es fan paleses unes mineralitzacions ferruginoses, les qual es situen sobre aquestes calcàries del Gargasià. Tot i això, aquestes mineralitzacions són poc importants. (fotografia 3).

Terra endins.2015 n.2 | Recorregut de recerca geològica i mineralògica pel pais de Fois / Foix (França): des de Sant Paul de Jarrat, a Freychenet. Col de la Lauze, Montferriér, i a Montsegur 


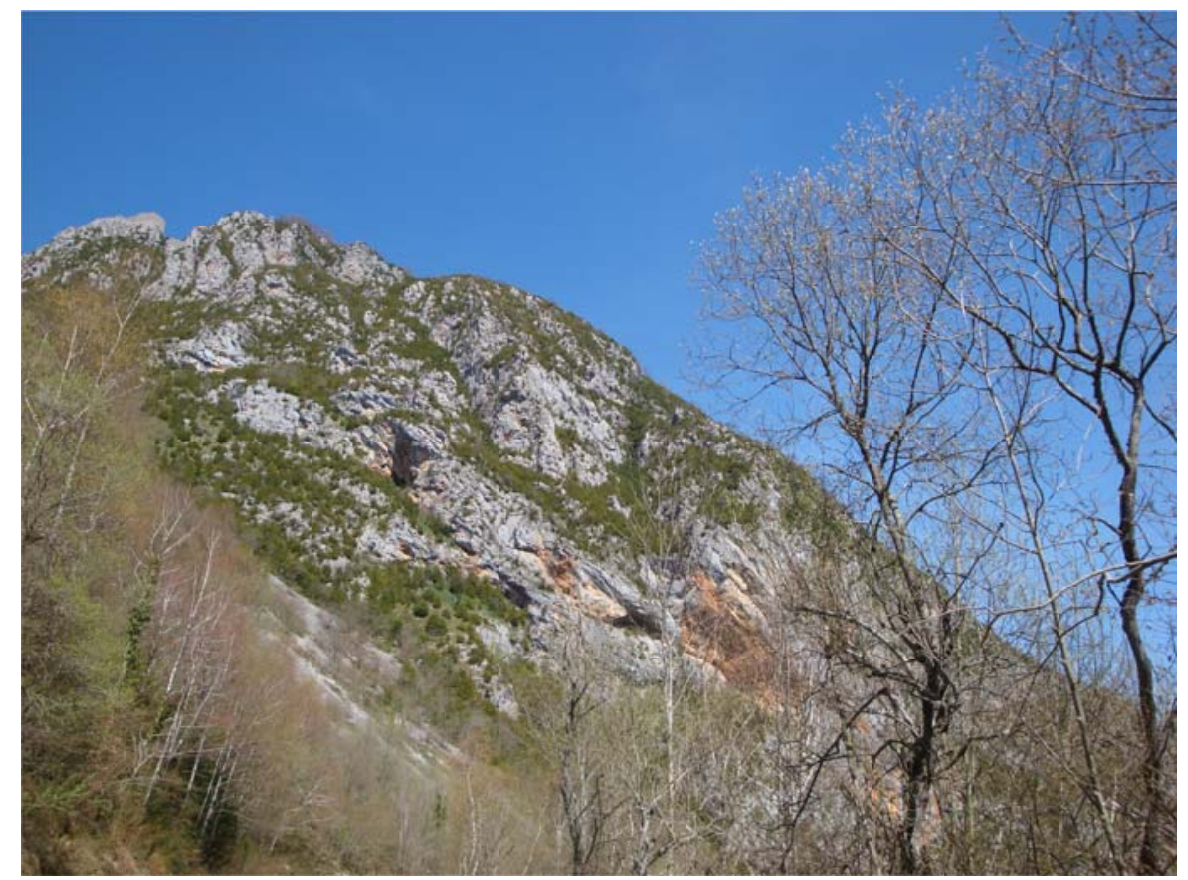

FOTOGRAFIA 3. Mineralitzacions ferruginoses situades sobre les calcaries del Turó del Chatieau de Montsegur.

El recorregut de l'itinerari finalitza en aquest Iloc

\section{Bibliografia emprada}

BRGM (1970a).- Carte géologique de France a 1/50.000. Fuille d'Ax - les- Termes. Direcction du Service Geéologique et des Labotatoires. Orleans - Source

BRGM (1970a).- Carte géologique de France a 1/50.000. Foix. Direcction du Service Geéologique et des Labotatoires. Orleans - Source

BRGM (1970a).- Carte géologique de France a 1/50.000. Lavelanet. Direcction du Service Geéologique et des Labotatoires. Orleans - Source 